\title{
Multiobjective optimization in an unreliable failure-prone manufacturing system
}

\author{
Jean-François Boulet ${ }^{\mathrm{a}}$, Ali Gharbi $\mathrm{i}^{\mathrm{a},}{ }^{,}$, Jean-Pierre Kenné ${ }^{\mathrm{b}}$ \\ ${ }^{a}$ Automated Production Engineering Department University of Québec \\ Production Systems Design and Control Laboratory (C2SP), \\ ${ }^{b}$ Mechanical Engineering Department
}

École de technologie supérieure, Mechanical Engineering Department, 1100, Notre-Dame Street West, Montréal(QC), Canada, H3C 1K3

\begin{abstract}
Purpose - This article considers a corrective and preventive maintenance model with a view to both minimizing cost and maximizing system availability. The model examined is based on a $m$ identical machine system subject to unpredictable breakdown and repair, and the maintenance strategy used is based on the existing block-replacement policy, which consists in replacing components upon failure or preventively, at scheduled intervals (T). Spare part inventory management is based on the (S, Q) model, whereby an order is placed when the replacement stock level drops below a given safety threshold level (S). At that time, a replacement part quantity $(\mathrm{Q})$ is ordered, and is received after a stochastic lead time $(\tau)$.

Design/methodology/approach - The experimental multiobjective proposed approach combines a simulation model and a statistical method (desirability approach, experimental design, response surface methodology and variance analysis (ANOVA)) to determine the best system parameters. The desirability function is used to convert a multiresponse problem into a maximization problem with a single aggregate measure.
\end{abstract}

Finding - The proposed model jointly minimizes the overall maintenance cost and maximizes system availability using a multiobjective optimization desirability function.

Practical implication - The multiobjective model can be used in a real manufacturing environment to help business decision makers determine the best compromise system parameters and adjust said parameters to obtain desired response variables (overall production cost and system availability).

Originality/value - The proposed model allows the simultaneous optimization of two response variables, and determines the best system parameter compromise between the system cost minimization and the system availability maximization.

Keywords: Maintenance policies, Desirability function, Multiresponse system, Simultaneous optimization, Experimental design and simulation, Response Surface Methodology.

Paper type: Research paper

\section{Introduction}

In a real production environment, equipment failure could have serious consequences on the competitiveness of a company. It is therefore crucial to have a maintenance program in place 
in order to increase the reliability, and thus, the availability, of production equipment. Preventive maintenance (PM) strategies constitute one possible solution for achieving this goal. By dictating preventive maintenance intervention sequences, these strategies seek to minimize the impact on production equipment. Over the last few decades, the scientific literature has developed several preventive maintenance strategies adapted to different industrial contexts [15]. It is indeed possible to group all those policies into two distinct policy categories: age replacement policy (ARP) and block replacement policy (BRP). The ARP, characterized by equipment utilization, consists in replacing equipment upon failure, or preventively, following a predetermined utilization time. Barlow \& Hunter [2] analyzed several characteristics of this policy, and determined that implementing it however requires continuous tracking of equipment utilization time; this makes it difficult to implement this strategy in a real production environment. The second policy, the block replacement policy (BRP), does not pose this implementation disadvantage. It consists in replacing equipment upon failure or after fixed intervals. The mathematical bases of the block replacement policy were developed by Barlow \& Hunter [2] and Barlow \& Proschan [3], after which several extensions of the BRP then went on to be developed. First, Cox [11] and Crookes [12] developed certain models using minimal repairs at the corrective maintenance (CM) interventions. Bhat [4] showed that it is more advantageous to utilize used components for corrective replacements, while Tango [27] proposed a mixed strategy, in which corrective maintenance can be carried out with used or new components. Working on this premise, several authors utilizing a single response variable have found optimal replacement policies in order to minimize the average cost per unit of time [8, 22 and 28]. However, models focused on cost optimization assume that maintenance duration is negligible as compared to operation time. Furthermore, to simplify the mathematical modelling employed, spare part inventory is assumed to be infinite. These two assumptions imply that the models cannot consider system availability. In some specific continuous processes, production equipment availability is very important; for example, in the pulp and paper industry a breakdown can lead to very high profit losses, and have a significant repercussion on the entire production process. The situation is similar for the metallurgy industry. For that reason, some researchers take maintenance duration into account in a bid to optimize equipment availability [26 and 29]. However, in such models, the replacement part inventory is also considered infinite, which does not represent reality. In fact, in the spare inventory backlog case, maintenance cannot be performed, leading to a decrease in system availability. Some authors have studied the effect of the spare-provisioning policy on the preventive maintenance strategies [1,6 and 10]. However, those entire models have considering the purchasing lead time negligible [1] or constant and shorter than the preventive replacement period [6 and 10]. Those assumptions restricted the model to some specific structure and limited their application in real manufacturing case.

Decision maker are generally interested in both a minimization of cost and a maximization of system availability. In this paper, we propose a model based on the existing corrective and preventive maintenance model, already developed in the literature, which consists of both a minimization of cost and a maximization of system availability, with a multiobjective optimization desirability approach. This alternative approach, used by [5, 18 and 21], consists to combining a simulation-based experimental design with a desirability approach in order to obtain an optimal solution for both response variables. For detailed information about the applied technique in the desirability approach, see Harrington [18], Derringer \& Suich [14] and Derringer [13]. This technique was proposed because the mathematical model cannot take different measure units (\$ and \%) into account in the multiobjective optimization approach. 
The model covered in this paper is based on $m$ identical machines subject to unpredictable breakdown and repair combined with an inventory control policy to manage the replacement of parts used in maintenance activities (corrective and preventive). The spare part inventory management model is $(\mathrm{S}, \mathrm{Q})$, meaning that when the replacement stock level drops below a safety threshold level (S), then a replacement part quantity (Q) is ordered, and will be available for consumption after a certain stochastic purchasing lead time $(\tau)$.

\section{Multiple-attribute decision analysis}

In a real production environment, the two performance criteria (overall maintenance cost and equipment availability) are very important, but the parameters which individually optimize each response variable are contradictory. To maximize system availability, business decision makers must provide a significant budget for maintenance activities. So the equipment availability maximization deteriorates the overall maintenance cost and vice versa. This divergence in objectives requires that a compromise, not the optimal solution, be found. Optimization aims to determine a compromise position between overall cost minimization and equipment availability maximization. With this performance objective in mind, it is interesting to simultaneously analyze the cost-effectiveness and the production equipment availability for different maintenance policy parameters. Moreover, these two responses cannot be compared directly as they use different units of expression. The main difficulty with this simultaneous optimization is the lack of an analytically efficient method for solving this multiobjective optimization approach [13]. That is why most of the models in the literature consider just a single response variable. Many techniques have been developed to simultaneously analyze various factors, with a view to providing decision makers with a satisfactory solution which simultaneously takes all these factors into account. Let us look at some of the most commonly used multiobjective optimization techniques, and discuss its applicability to our case.

\section{Goal Programming method}

Goal programming is a multiple-attribute decision analysis technique that is capable of handling multiple conflicting objectives by taking priorities into account [7]. In goal programming, the objective function attempts to minimize the deviation between the goal and what can be achieved within the given set of a constant. This technique was introduced by Charnes [9] in 1961 for solving linear, multiple-objective mathematical programming nonlinear problems. The main difficulty with the multiobjective goal programming approach lies in formulating the model, which is effectively the process of transforming a real manufacturing environment decision problem into a mathematical model with objective variables and constraints. In our case, the manufacturing facility cannot be formulated linearly with a reasonable number of variables and constraints, and so the goal programming approach cannot be used to provide a satisfactory solution to our multiple-objective problem.

\section{Analytic Hierarchy Process method (AHP method)}

The analytic hierarchy process is a way used to break down a complex and unstructured situation into its component parts. This method arranges criteria and alternatives into a hierarchic order and assigns numeral values to subjective judgments on the relative importance of each element of the hierarchy and alternatives from whom we have to make the best selections. Finally, this approach aggregates the judgment to determine which alternative should have the highest priority, and should be acted upon in order to influence the outcome 
of the situation [25]. This method is especially used in complex situations, and takes into account both tangible (system cost, system availability or production rate) and intangible factors (environment, customer satisfaction or labour relation and motivation). In our multiple-objective problems, the two performance criteria (overall maintenance cost and equipment availability) are tangibles and the alternative are not known in advance. Consequently, analytic hierarchy process (AHP) methods cannot easily be adapted to our problem.

\section{Desirability approach}

The desirability approach converts a multiple-attribute problem into a maximization problem with a single aggregate measure, and solves it as a single maximization objective optimization problem. The desirability function approach transforms an estimated response to a scale-free value. This simultaneous multiple-objective approach uses a factor codification system with values ranging between 0 and 1 . This approach takes into account the optimization objective (minimization or maximization) in the factor codification attribution. Because of its simplicity and its applicability to our case, we favoured this approach in determining the best compromise between system cost minimization and system availability maximization.

\section{Problem statement}

The ideal optimal solution, where the two response variables parameters are at their optimum values, cannot be reached. Indeed, the parameters which optimize each individual response variable are contradictory, thus leading to a desirability approach being favoured. This approach consists in optimizing each response variable individually in order to maximize the combination of each codified response variable. Before simultaneously analyzing the two response variables, it is essential to optimize them separately first.

$\begin{array}{ll}\text { Notations } & \\ \mathrm{C}_{\mathrm{T}} & \text { Total maintenance cost } \\ \mathrm{C}_{\mathrm{R}} & \text { Replacement cost (PM or CM) } \\ \mathrm{C}_{\mathrm{I}} & \text { Inventory cost } \\ \text { MDT } & \text { Mean Downtime (PM or CM) } \\ \text { MTTF } & \text { Mean Time To Failure } \\ \text { MTTM } & \text { Mean Time To Maintenance (PM) } \\ \text { MTTR } & \text { Mean Time To Repair (CM) } \\ \text { Q } & \text { Ordered replacement part quantity } \\ \text { S } & \text { Replacement part safety threshold level (Ordered point) } \\ \text { T } & \text { Block-replacement policy cycle length }\end{array}$

\section{Assumptions}

1. The preventive replacement cost is lower than the corrective replacement $\operatorname{cost}\left(\mathrm{c}_{2}<\mathrm{c}_{1}\right)$

2. The time for a preventive maintenance is shorter than the time for a corrective maintenance.

3. The purchasing lead time $(\tau)$ is independent of the ordered quantity $(Q)$.

4. No reduction is granted according to the ordered replacement part quantity $(Q)$.

5. At each reorder point, a sufficient replacement part quantity $(\mathrm{Q})$ is available

\section{Cost model}

The total maintenance cost is represented by the sum of the replacement and the spare part inventory costs: 
$C_{T}=\frac{C_{R}+C_{I}}{T}$

To preserve a common base, each cost (maintenance interventions and replacement part inventory) must be defined on the interval $[\mathrm{k} \mathrm{T},(\mathrm{k}+1) \mathrm{T}]$,

where $\mathrm{k}=1,2, \mathrm{n}$.

$$
\begin{aligned}
& C_{R}=c_{1} \cdot E\left[x_{c m}\right]+c_{2} \\
& C_{I}=\left[k+p \cdot\left(1+E\left[x_{c m}\right]\right)\right]+\left[b \cdot E\left[x_{b}\right]\right]+\left[c^{+} \cdot x^{+}(t)\right]
\end{aligned}
$$

where: $c_{1}=C M \operatorname{cost} ; c_{2}=P M \operatorname{cost} ; k=$ order cost $; \mathrm{p}=$ part cost; $\mathrm{E}\left[\mathrm{x}_{\mathrm{cm}}\right]=\mathrm{CM}$ mean number between two PM intervals; $\mathrm{b}=$ backlog cost; $\mathrm{E}\left[\mathrm{x}_{\mathrm{b}}\right]=$ mean number of replacement part backlog between two PM intervals; $\mathrm{c}^{+}=$Inventory cost, $\mathrm{x}^{+}(\mathrm{t})=$ replacement part stock

\section{Availability model}

System availability, illustrated in Figure 1, takes into account the unavailability period for maintenance activities (CM and PM) and for the spare part backlog. This figure represents the different maintenance possibilities that can appear in a real production environment. Firstly, at each PM interval time $(\mathrm{k} \cdot \mathrm{T})$, a preventive maintenance is performed, in order to prevent the $\mathrm{CM}$. Thereafter, if a breakdown appears during the production state, a CM intervention is performed, and the system returned to the production mode until the next maintenance intervention. Finally, if the CM intervention ended after the next planned PM replacement time scheduled at time $[\mathrm{k} \cdot \mathrm{T}]$, this planned PM is skipped, and the next PM activity is performed at time $[(\mathrm{k}+1) \cdot \mathrm{T}]$. In each case, if replacement parts are not available at the replacement time, the system must wait to receive the next spare part order before performing the maintenance intervention (PM or CM).

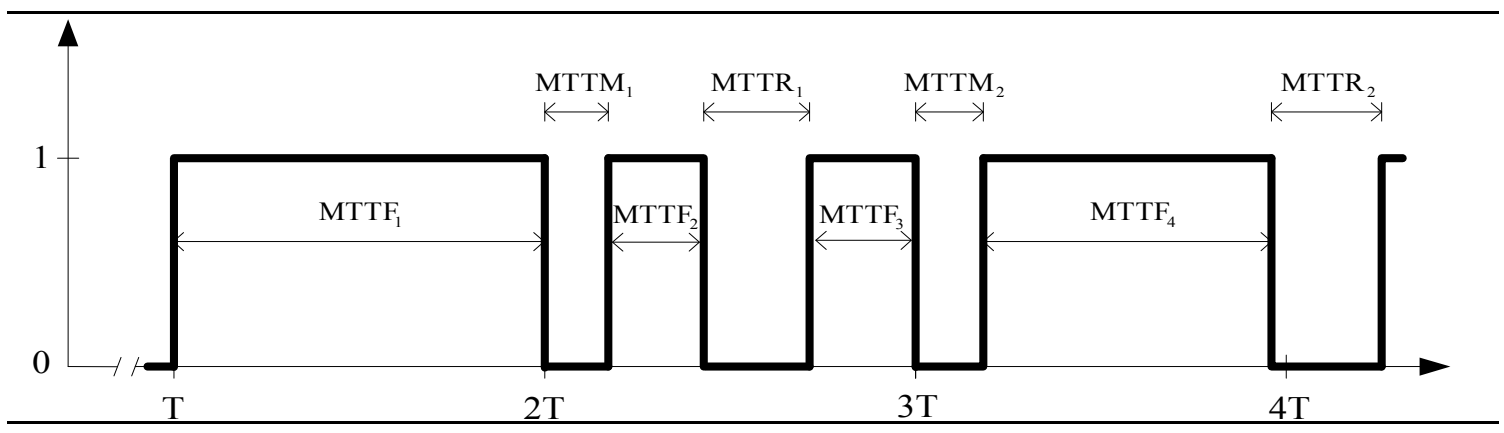

Fig. 1. System availability diagram

The MTTR and MTTM represent the mean time to repair for corrective and preventive maintenance activities, respectively. Equation (4) represents the system operation time percentage and defines the system availability.

$$
\text { Availability }=\frac{\text { MTTF }}{(\mathrm{MDT})+\mathrm{MTTF}}
$$

Because of a lack of efficient methods for analytically solving a multiobjective optimization [16], an experimental approach is favoured in determining the parameters that minimize cost and maximize production equipment availability. This experimental approach is also used to 
determine the optimal parameters for each response variable (cost and system availability) individually.

\section{Proposed approach and simulation model}

In this paper, we have adopted an experimental approach used in Gharbi and Kenne [17] to determine each response variable (cost and system availability) individually. This approach consists of a simulation model and a statistical method (experimental design, response surface methodology and variance analysis (ANOVA)) combination used to determine the optimal parameters for each model. This experimental approach structure consists of the following sequential steps:

- $\quad$ The experimental design approach defines the method for varying decision variables.

- The system dynamic is represented by a discreet event simulation model (see Figure 1 ) in order to individually obtain each response variable (cost and system availability) associated with each simulation experimental parameters set.

- The statistical analysis step is used to obtain the relationship between the incurred response variable (cost and system availability) and significant main factor and interactions given by the variance analysis.

- The desirability approach (bound determination, codification and desirability function (D)) is used to determine the multiobjective optimization.

- The final step is to validate the model's robustness through a sensitivity analysis.

We will now present the simulation concept used. A discreet event simulation model is used to describe the system dynamics using the Visual SLAM language [24]. This model consists of several networks, each of which describes a specific task (breakdown generation, repair policy and replacement part inventory control).

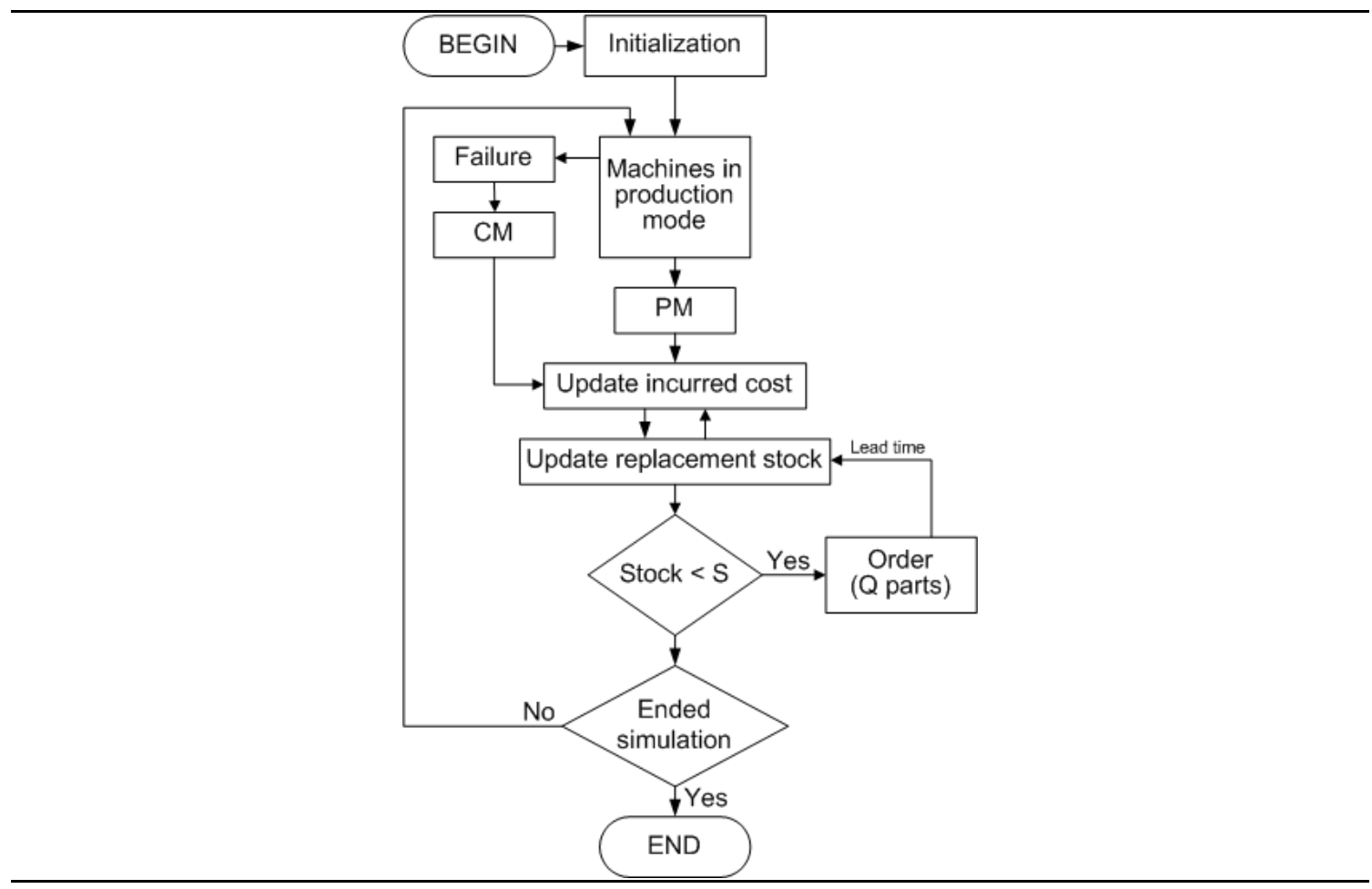

Fig.2: Simulation model diagram 
This figure represents the concepts that we use in our simulation model.

\section{Experimental design and response surface methodology}

In the following section, we use the system parameters presented in the Tables 1 and 2 . These parameters were chosen to highlight the system behaviour described in the previous sections.

Table 1:

System data

\begin{tabular}{cccccc}
\hline $\mathrm{m}$ & $\mathrm{c}_{1}$ & $\mathrm{c}_{2}$ & $\mathrm{c}_{\mathrm{p}}$ & $\mathrm{c}_{\mathrm{o}}$ & $\mathrm{c}_{\mathrm{i}}$ \\
\hline 2 & 3900 & 1900 & 100 & 200 & 1000 \\
\hline Where & $\mathrm{m}=$ Number of machines; $\mathrm{c}_{1}=$ Corrective maintenance cost; $\mathrm{c}_{2}=$ Preventive maintenance cost; \\
& $\mathrm{c}_{\mathrm{p}}=$ Parts cost $; \mathrm{c}_{\mathrm{o}}=$ Order cost; $\mathrm{c}_{\mathrm{i}}=$ Inventory cost;
\end{tabular}

Table 2:

Probability distributions of system parameter

\begin{tabular}{cccc}
\hline$\tau$ & MTTF & MTTR & MTTM \\
\hline$\sim \operatorname{lognormal}(25.5)$ & $\sim \operatorname{lognormal}(200.100)$ & $\sim \operatorname{lognormal}(50.5)$ & $\sim \operatorname{lognormal}(5.1)$ \\
\hline Where & $\tau=$ purchasing lead time; MTTF = Mean Time To Failure; MTTR & Mean Time To Repair \\
& $(\mathrm{CM}) ;$ MTTM = Mean Time To Maintenance $(\mathrm{PM})$
\end{tabular}

In this study, we collect and analyze data in steady state. Due to the convexity property of the two functions (cost and availability) [16], we choose a $3^{3}$ ( 3 factors having each 3 modalities) response surface design for both response functions. This experimental approach is used to study and understand the effects between independent variables ( T, S and Q) and two response functions (cost and system availability). In order to understand the system variability, four replications were conducted for each combination of factors. To determine the variables range (Table 3), we used some offline simulations in order to center the response function domains.

Table 3

Independent variables levels

\begin{tabular}{ccccc}
\hline & & Cente & \\
Factors & Low level & $\mathrm{r}$ & High level & Description \\
\hline $\mathrm{T}$ & 60 & 110 & 160 & Preventive maintenance point \\
$\mathrm{S}$ & 0 & 1 & 2 & Ordering point \\
$\mathrm{Q}$ & 2 & 3 & 4 & Quantity in each order \\
\hline
\end{tabular}

The response surface methodology was used to optimize the simulation result. This method is a collection of mathematical and statistical techniques that are useful for modeling and analyzing problems in which a response is influenced by several variables [23]. In our case, the model contains three input variables (T, S and Q) and two response variables (cost and system availability). For each response variable, we assume here that there exists a function $\Phi$ on $\mathrm{z}_{1}, \ldots, \mathrm{z}_{\mathrm{n}}$ that provides the response variable value corresponding to any given input factor combination. This function $\Phi($.$) is called the response surface, and is assumed to be a$ continuous function of $\mathrm{z}_{\mathrm{j}}, \mathrm{j}=1, \ldots, \mathrm{n}$. Due to the convexity property of the value function, the first-order response surface method is rejected. We choose the second-order model given by:

Response variables (Cost or Availability) $=\beta_{0}+\sum_{i=1}^{n} \beta_{i} Z_{i}+\sum_{i=1}^{n} \beta_{i i} Z_{i}^{2}+\sum_{i=1}^{n-1} \sum_{j=2, i<j}^{n} \beta_{i j} Z_{i} Z_{j}+\varepsilon$ 
where $\mathrm{Z}_{\mathrm{j}}=\mathrm{z}_{\mathrm{j}}, \mathrm{j}=1, \ldots, \mathrm{n}$ are the input variables; $\beta_{0}, \beta_{i}(\mathrm{i}=1,2,3), \beta_{i j}(\mathrm{i}, \mathrm{j}=1,2,3)$ are unknown parameters, and $\varepsilon$ is a random error.

\section{Result analysis}

The statistical analysis is performed using a multifactor variance analysis (ANOVA), which uses a statistical software application, such as STATGRAPHICS, to provide the three independent variables effect on each dependant variable (cost and availability). Tables 4 and 5 illustrate a particular ANOVA, especially designed for regression analysis, which corresponds to the generated data.

Table 4

Cost ANOVA table

\begin{tabular}{lccccc}
\hline Source & Sum of square & df & Mean Square & F-ratio & P-value \\
\hline $\mathbf{T}$ & 64169.6 & 1 & 64149.6 & 72349.88 & 0.0000 \\
$\mathbf{S}$ & 5372.66 & 1 & 5372.66 & 6057.57 & 0.0000 \\
$\mathbf{Q}$ & 1222.54 & 1 & 1222.54 & 1378.39 & 0.0000 \\
$\mathbf{T}^{2}$ & 6620.4 & 1 & 6620.4 & 7464.37 & 0.0000 \\
$\mathbf{T S}$ & 95.78 & 1 & 95.78 & 107.99 & 0.0000 \\
$\mathbf{T Q}$ & 15.5 & 1 & 15.5 & 17.48 & 0.0001 \\
$\mathbf{S}^{2}$ & 44.49 & 1 & 44.49 & 50.17 & 0.0000 \\
$\mathbf{S Q}$ & 12.99 & 1 & 12.99 & 14.65 & 0.0002 \\
$\mathbf{Q}^{2}$ & 2 & 1 & 2 & 2.26 & 0.1364 \\
Residual & 84.25 & 95 & 0.89 & & \\
Total & 77640.21 & 104 & \multicolumn{3}{c}{ R-Squared $=0.9981$} \\
\hline
\end{tabular}

Table 5

Availability ANOVA table

\begin{tabular}{lccccc}
\hline Source & Sum of square & df & Mean Square & F-ratio & P-value \\
\hline $\mathbf{T}$ & 617.83 & 1 & 617.83 & 1472.56 & 0.0000 \\
$\mathbf{S}$ & 42.46 & 1 & 42.46 & 101.21 & 0.0000 \\
$\mathbf{Q}$ & 3.51 & 1 & 3.51 & 8.36 & 0.0047 \\
$\mathbf{T}^{2}$ & 198.23 & 1 & 198.23 & 472.46 & 0.0000 \\
$\mathbf{T S}$ & 37.02 & 1 & 37.02 & 88.24 & 0.0000 \\
$\mathbf{T Q}$ & 0.91 & 1 & 0.91 & 2.18 & 0.1434 \\
$\mathbf{S}^{\mathbf{2}}$ & 14.15 & 1 & 14.15 & 33.74 & 0.0000 \\
$\mathbf{S Q}$ & 3.97 & 1 & 3.97 & 9.47 & 0.0027 \\
$\mathbf{Q}^{2}$ & 1.16 & 1 & 1.16 & 0.39 & 0.5360 \\
Residual & 39.86 & 95 & 0.38 & & \\
Total & 959.1 & 104 & \multicolumn{3}{c}{ R-Squared $=0.9584$} \\
\hline
\end{tabular}

For each main effect, interaction and quadratic effect, Tables 4 and 5 each presents the sum of squares, the degree of freedom (df), the mean square, an F-ratio, computed using the residual mean squares, the degree of freedom and the mean square for the residual. From The tables present the factors (mains factors, interactions and quadratics effects) significant at a 0.05 level (if P-value $>5 \%$, the factor is non significant). In the next figure (Response Function Pareto Chart), we have a graphical illustration of the effect of each factor and its weight on each response variable (cost and availability). 


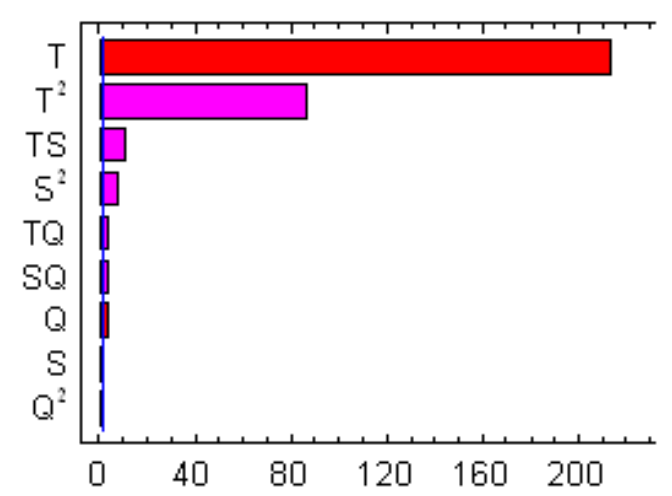

(a) Cost

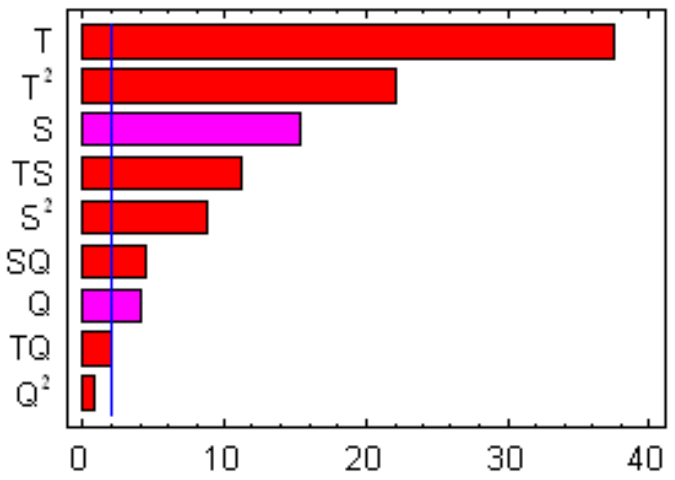

(b) Availability

Fig. 3. Response Function Pareto Chart

Based on tables 4 and 5, the derived cost and availability models are represented by the following equations:

$$
\begin{array}{ll}
\text { Cost }=\quad & 148.21-1.3958 \mathrm{~T}-6.2664 \mathrm{~S}-3.57 \mathrm{Q}+0.0046 \mathrm{~T}^{2}+0.0218 \mathrm{~T} \cdot \mathrm{S}+0.0093 \mathrm{~T} \cdot \mathrm{Q} \\
& +1.1947 \mathrm{~S}^{2}+0.4285 \mathrm{~S} \cdot \mathrm{Q} \\
\text { Availability }= & 79.6352+0.1517 \mathrm{~T}+4.6475 \mathrm{~S}+1.1933 \mathrm{Q}-0.0008 \mathrm{~T}^{2}-0.0138 \mathrm{~T} \cdot \mathrm{S}-0.7643 \mathrm{~S}^{2} \\
& -0.2797 \mathrm{~S} \cdot \mathrm{Q}
\end{array}
$$

The third-order interactions and all other effects were neglected or added to the error. More details on the response surface methodology can be found in Khuri and Cornell [20].The adjusted correlation coefficient $\left(\mathrm{R}^{2}\right.$ adj $)$ also indicates that over $95 \%$ of system variability is explained by the model (see Tables 4, 5 and 6). The fact that adjusted correlation coefficients are high in all models and residue analyses loosens no tendency, indicates that the answer variable is clear enough to have no appeal to transformation. With the simulation and statistical analysis combination, we experimentally determine the optimal parameters $(T, S$ and Q) for the system cost and for production equipment availability (see Table 4).

Table 6:

Optimal parameters

\begin{tabular}{ccccccc}
\cline { 2 - 6 } & $\mathrm{T}$ & $\mathrm{S}$ & $\mathrm{Q}$ & Cost & Availability & $\mathrm{R}_{\text {adj }}^{2}$ \\
\hline Cost optimization & 145.80 & 0.71 & 3.24 & $\mathbf{4 0 . 1 3}$ & $87.48 \%$ & $99.81 \%$ \\
\hline Availability optimization & 78.53 & 1.64 & 3.77 & 56.67 & $\mathbf{9 1 . 9 4} \%$ & $95.85 \%$ \\
\hline
\end{tabular}

The response surface contour shows (Figure 4) the optimal parameters for each individual response variable and confirms the convexity of the cost and availability functions. 


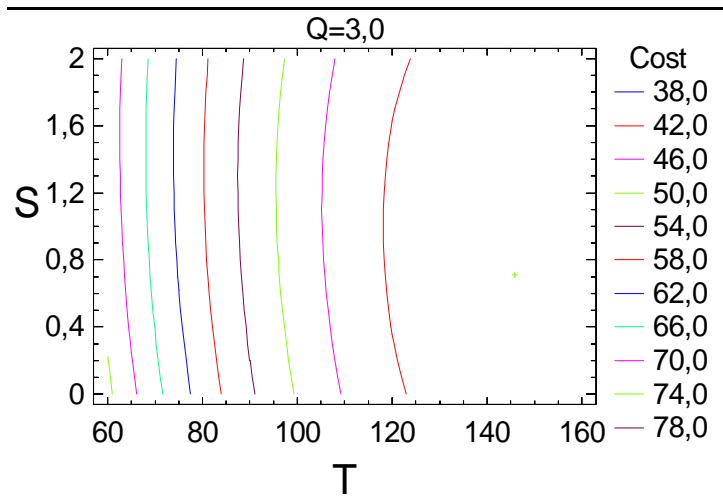

(a) Cost

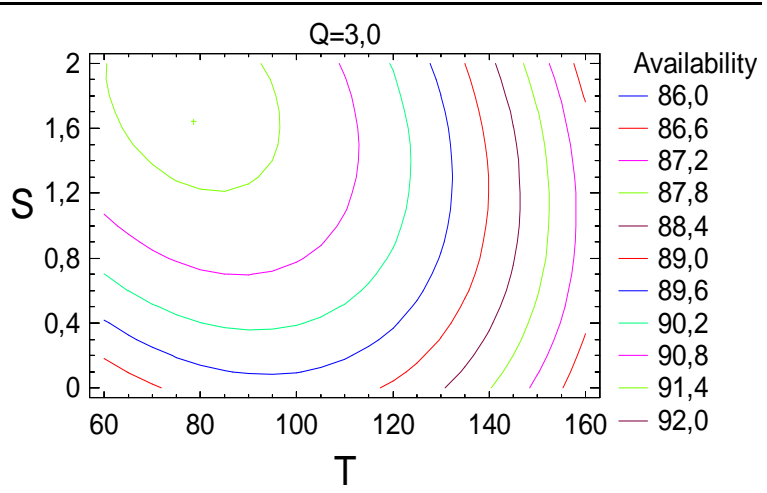

(b) Availability

Fig. 4. Response surface contour plot

\section{Desirability}

The ideal solution, where the two response variables are set to their optimum values, cannot be reached because the factor values (T, S and Q) which optimize the two response variables individually are not necessary the same. For that reason, the desirability approach converts a multiresponse problem into a maximization problem with a single aggregate measure and solves it as a single maximization objective optimization problem.

\section{Desirability function approach}

The desirability function approach transforms an estimated response to a scale-free value, $\mathrm{d}_{\mathrm{k}}$, called desirability. It is a value between 0 and 1 , and increases as the desirability of the corresponding response increases [21]. The global desirability, D, developed by Harrington [18], is defined by combining different $\mathrm{d}_{\mathrm{k}}$ values (see Equation 8 below).

$D=\left(d_{1} \times d_{2} \times \ldots \times d_{r}\right)^{1 / r}$

Based on the pioneering work of Harrington [18] and Derringer \& Suich [14] on the subject of desirability, Derringer [11] extended the desirability approach by including the response variable relative weight in the global desirability function (D):

$D=\left(d_{1}^{w 1} \times d_{2}^{w 2} \times \ldots \times d_{r}^{w r}\right)^{1 / \Sigma w r}$

where the $\mathrm{w}_{\mathrm{j}}$ instances are the relative weights among the $\mathrm{r}$ responses, $\mathrm{j}=1,2, \ldots, \mathrm{r}$. With this desirability approach, each response variable can have a different effect on the global optimal solution. In the specific case where all the relative weights $\left(\mathrm{w}_{\mathrm{j}}\right)$ are set to 1 , the Derringer [13] desirability approach is the same as the Harrington [18] approach, thus implying that the Harrington [17] desirability approach is in effect a specific case of the Derringer [13] desirability approach.

\section{Desirability bounds determination}

The bounds of each individual response variable $\left(\mathrm{y}_{\mathrm{j}}^{\min }\right.$ and $\left.\mathrm{y}_{\mathrm{j}}{ }^{\mathrm{max}}\right)$ are set at the extreme values of each individual response. This value will be used to determine the codified value for each response variable. 


$$
\begin{aligned}
& y_{j}^{\text {min }}=\min _{\mathrm{x} \in \Omega}\left\{\mathrm{y}_{\mathrm{j}}(\mathrm{T}, \mathrm{S} \text { and } \mathrm{Q})\right\} \\
& y_{j}{ }^{\max }=\max _{\mathrm{x} \in \Omega}\left\{\mathrm{y}_{\mathrm{j}}(\mathrm{T}, \mathrm{S} \text { and } \mathrm{Q})\right\}
\end{aligned}
$$

In this specific case, $\mathrm{y}_{1}$ represents the cost response variable and $\mathrm{y}_{2}$ represents the system availability response variable. The bounds determined by Equations (10) and (11) represent the minimum and the maximum values of the individual response variable (cost and system availability) within the experimental region $\Omega$.

\section{Desirability codification}

This simultaneous multiobjective optimization approach uses a factor codification system, with the codification factors varying with the objective (minimization or maximization) of each response variable. Figure 5 illustrates each codification case.

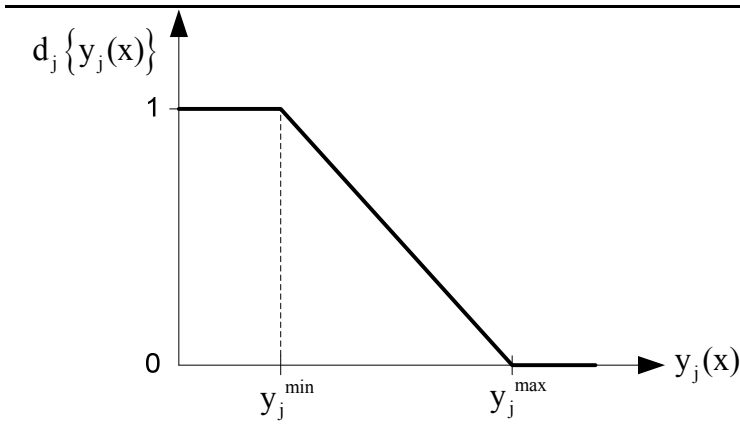

(a) Response minimization

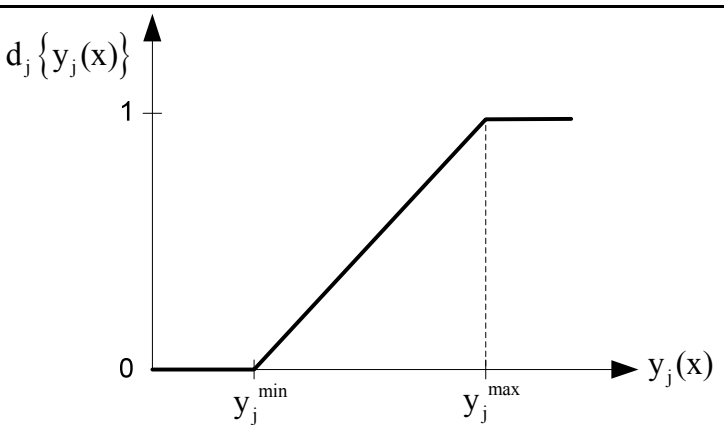

(b) Response maximization

Fig. 5 Desirability codification

In this paper, each response variable has a different objective. The cost and system availability response variables are respectively subject to a minimization and to a maximization. In each case, the response variable needs to be codified (value between 0 and 1 ) in order to compare it with the desirability function (see Equation (9)). For the cost response desirability $\left(\mathrm{d}_{1}\right)$, the minimum value takes the maximum codification value $(1)$ and the rest of the values decrease linearly according to Equation (12) until the maximum cost value which takes the minimum codification value (0). The system availability response variables use the same approach, but in the opposite direction (see Equation (13)). In other words, we penalize the lowest value and improve the biggest values.

$$
\begin{aligned}
& d_{1}=\left\{\begin{array}{cc}
1 & \text { if } y_{1} \leq y_{1}{ }^{\min } \\
\frac{\left(y_{1}^{\max }-y_{1}\right)^{s}}{\left(y_{1}^{\max }-y_{1}^{\min }\right)^{s}} & \text { otherwise } \\
0 & \text { if } y_{1} \geq y_{1}^{\max }
\end{array}\right. \\
& d_{2}=\left\{\begin{array}{cc}
0 & \text { if } y_{2} \leq y_{2}{ }^{\min } \\
\frac{\left(y_{2}-y_{2}{ }^{\min }\right)^{s}}{\left(y_{2}{ }^{\max }-y_{2}{ }^{\min }\right)^{s}} & \text { otherwise } \\
1 & \text { if } y_{2} \geq y_{2}{ }^{\max }
\end{array}\right.
\end{aligned}
$$


The shape factor (s) is set to 1 for each desirability $\left(d_{1}\right.$ and $\left.d_{2}\right)$. With these transformations (Equations (12) and (13)), it is possible to simultaneously analyze the cost-effectiveness and the equipment availability for different maintenance policy parameters using the desirability function (Equation (9)).

\section{Sensitivity analysis}

To illustrate the model's robustness, a sensitivity analysis on the desirability approach is conducted. In this analysis, we varied the relative weight $\left(\mathrm{w}_{1}\right.$ and $\left.\mathrm{w}_{2}\right)$ of each response variable $\left(\mathrm{d}_{1}\right.$ and $\left.\mathrm{d}_{2}\right)$, in order to ensure that the optimum parameters for the simultaneous optimizations go in the right and logical direction. Moreover, we checked to see if the model's behaviour is realistic by comparing the optimum parameters for each individual response variable with the multiobjective optimum parameters (Table 7). This analysis shows the benefit obtained with the desirability approach (Table 7; case3). This case represents the maintenance budget needed to obtain a compromise between maximum system availability (high maintenance budget) and minimum system availability (low maintenance budget).

Table 7:

Sensitivity analysis

\begin{tabular}{|c|c|c|c|c|c|c|c|c|}
\hline \multirow[b]{2}{*}{ Case } & \multicolumn{6}{|c|}{$\mathrm{S}^{*}$} & Availabilit & \multirow[t]{2}{*}{ Comments } \\
\hline & $\mathrm{w}_{1}$ & $\mathrm{~W}_{2}$ & $\mathrm{~T}^{*}$ & & $Q^{*}$ & Cost & $\mathrm{y}$ & \\
\hline 1 & 1 & $\mathbf{0}$ & 145.8 & 0.71 & 3.24 & 40.13 & $87.48 \%$ & Cost $^{*}$ \\
\hline 2 & $\mathbf{0}$ & 1 & 78.5 & 1.64 & 3.77 & 56.67 & $91.94 \%$ & Availability $^{*}$ \\
\hline 3 & 1 & 1 & 109.3 & 1.27 & 3.62 & 44.75 & $90.54 \%$ & Desirability Case \\
\hline 4 & 1 & 2 & 103,4 & 1.32 & 3.68 & 46.21 & $90.98 \%$ & Cost $\uparrow ;$ Availability $\uparrow$ \\
\hline 5 & 1 & 5 & 95,2 & 1.42 & 3.69 & 48.82 & $91.47 \%$ & Cost $\uparrow ;$ Availability $\uparrow$ \\
\hline 6 & 1 & 10 & 89.5 & 1.50 & 3.68 & 51.10 & $91.71 \%$ & Cost $\uparrow$; Availability $\uparrow$ \\
\hline 7 & 2 & 1 & 115.0 & 1.24 & 3.58 & 43.64 & $90.05 \%$ & Cost $\downarrow$; Availability $\downarrow$ \\
\hline 8 & 5 & 1 & 123.1 & 1.22 & 3.57 & 42.24 & $89.50 \%$ & Cost $\downarrow$; Availability $\downarrow$ \\
\hline 9 & 10 & 1 & 128.9 & 1.20 & 3.62 & 41.65 & $88.96 \%$ & Cost $\downarrow$; Availability $\downarrow$ \\
\hline
\end{tabular}

Here, $\mathrm{w}_{2}=0$ (case 1), indicates the optimum parameters for the cost analysis and $\mathrm{w}_{1}=0$ (case 2 ) indicates the optimum parameters for system availability analysis. Through the above analysis, it clearly appears that the results obtained make sense because all the results go in the right direction. By increasing the Availability relative weight (Table 7, case 4 to 6) we notice an increase in the overall maintenance cost. Furthermore, by increasing the Cost relative weight we see a drop in availability (Table 7, case 7 to 9). Effectively, by modifying each variable's relative weight $\left(\mathrm{w}_{1}\right.$ and $\left.\mathrm{w}_{2}\right)$, it is possible to get closer to each optimum response value. The sensitivity analysis also indicates the advantage of using a multiobjective approach to determine the compromise between each response variable's optimum parameters. That means that with this model, business decision makers have are able to adjust system parameters according to market demand. During certain financial periods, they may decide to reduce the maintenance budget and decrease equipment availability, while in other production periods, they may decide to increase production equipment availability by increasing the maintenance budget. 


\section{Conclusions}

In this paper, a multiobjective optimization desirability approach has been developed. This approach determines the best compromise parameters ( $T, S$ and $Q$ ) between cost minimization and system availability maximization. Because there was no effective method for analytically solving a multiobjective optimization, we favoured an experimental approach using the desirability approach. This methodology, which is based on experimental design and simulation, was used to solve our multiobjective problem. Compared to most models that have been developed in the scientific literature, which focus on a single response variable, this approach proposes the possibility, for the business decision maker, of determining the relative weight of each response variable. Thus, the importance level that the decision maker assigns to each response variable should be reflected in the optimal solution. This also means that maintenance parameters (T, S and Q) can be varied, depending on the order book and fiscal period, in order to adjust the desired budget cost and production equipment availability.

\section{References}

[1] Acharya, D., Nagabhushanam, G., Alam, S.S. (1986) Jointly optimal block replacement and spare provisioning policy, IEEE 87 Transactions On Reliability Vol. R-35(4).

[2] Barlow, R. E., \& Hunter. (1960), Optimal preventive maintenance policies. Operations Research, 8, pp. 90-100.

[3] Barlow R.E. \& Proschan F. (1965), Mathematical theory of reliability. Wiley, New York. [4] Bhat, B. R. (1969), Used Item Replacement Policy. Journal of Applied Probability 6, pp. 309-318.

[5] Boschian, V., Rezg, N., Chelbi, A. (2006), Apport de la simulation dans le choix d'une stratégie de maintenance pour des systèmes de production soumis à des périodes

d'indisponibilité. Actes de la 6e conférence francophone de modélisation et de simulation, Rabat, Maroc, 3-5 avril - CDROM.

[6] Brezavšèek, A., Hudoklin, A. (2003), Joint optimization of block-replacement and periodic review spare-provisioning policy., IEEE Transactions on Reliability, 52 (1), pp. 112117

[7] Canada, J.R. \& Sullivan, W.G. (1989), Economic and multiattribute evaluation of advanced manufacturing systems. Prentice Hall Inc., New Jersey.

[8] Canfield, R.V. (1986), Cost Optimization of Periodic Preventive Maintenance. IEEE Transaction on Reliability, Vol. R-35, No. 1. pp. 78-81.

[9] Charnes, A. \& Cooper, W.W. (1961), Management models and industrial applications of linear programming. Wiley, New York.

[10] Chelbi, A., \& Ait-Kadi, D. (2001), Spare Provisioning Strategy for Preventively Replaced Systems Subjected to Random Failure. International Journal of Production Economics, Vol. 74, 1-3, pp-183-189.

[11] Cox, D. R. (1962), Renewal Theory, John Wiley \& Sons Inc., New York.

[12] Cookes, P. C. I. (1963), Replacement Strategies. Operations Research Quarterly, 14, pp. 167-184.

[13] Derringer G. (1994), A Balancing Act: Optimizing a Product’s Properties. Qual. Prog., pp. 51-58.

[14] Derringer, G., Suich, R. (1980), Simultaneous Optimization of several Response

Variables. Journal of Quality technology, 12(4), pp. 214-219.

[15] Duffuaa, S.O., Raouf, A., Campbell, J.D. (1999), Planning and Control of Maintenance Systems. John Wiley and Sons, New York. 
[16] Gershwin, S.B. (1994), Manufacturing Systems Engineering. PTR Prentice Hall, Englewood Cliffs, NJ.

[17] Gharbi, A., Kenne, J.P. (2000), Production and preventive maintenance rates control for a manufacturing system: An experimental design approach. International journal of production economics. 65 pp. 275-287.

[18] Harrington, E. C. Jr. (1965), The Desirability Function. Industrial Quality Control. 21(10), pp. 494-498.

[19] Kralj, B. \& Petroviv R. (1995), A Multiobjective Optimization Approach to Thermal Generating Units Maintenance Scheduling. European Journal of Operational Research, Vol. 84, pp. 481-493.

[20] Khuri, A. I. and Cornell, J. A. (1987), Response Surfaces: Design and Analysis. Marcel Dekker.

[21] Kim, K. J., \& Lin, K. J. D. (2000), Simultaneous optimization of mechanical properties of steel by maximizing exponential desirability functions. Appl. Stat., pt. 3, vol. 49, pp. 311325.

[22] Lam, C.T. \& Yeh R.H. (1994), Optimal Maintenance - Policies for Deteriorating Systems Under Various [1] Maintenance Strategies. IEEE Transaction on Reliability, Vol. 43, No. 3, pp.423-430.

[23] Montgomery, D.C. (2000), Design and Analysis of Experiments. Fifth edition, John Wiley and Sons, New York.

[24] Pritsker, A. A. B., O’Reilly, J.J. (1999), Simulation with Visual SLAM and Awesim. John Wiley and Sons, New York.

[25] Saaty, T.L. (1980), The Analytic Hierarchy. Process, New York: McGraw-Hill.

[26] Sheu S.H. (1995), Extended block replacement policy of a system subject to shocks, IEEE Transaction on Reliability, Vol. 46.

[27] Tango, T. (1978), Extended block replacement policy with used items. Journal of Applied Probability, 15(3), pp. 560-572

[28] Valdez-Flores, C. \& Feldman R.M. (1989), A Survey of Preventive Maintenance Models for Stochastically Deterioration Single-Unit Systems. Naval research logistics, Vol. 36, pp. 419-446.

[29] Worthman, M.A., Klutke, G.-A., Ayhan, H. (1994), A maintenance strategy for systems subjected to determination governed by random shocks. IEEE Transaction on Reliability, Vol. 43, No. 3, pp. 439-445.

* Corresponding author: Ali Gharbi can be contacted at: ali.gharbi@etsmtl.ca 